\title{
AURÉLIE CHEVANELLE-COUTURE, Médée, mémoire du théâtre. Une Poétique du mal (1556-1713)
}

\section{Monica Pavesio}

\section{OpenEdition}

\section{Journals}

\section{Edizione digitale}

URL: https://journals.openedition.org/studifrancesi/43788

DOI: 10.4000/studifrancesi.43788

ISSN: 2421-5856

\section{Editore}

Rosenberg \& Sellier

\section{Edizione cartacea}

Data di pubblicazione: 1 juin 2021

Paginazione: $210-211$

ISSN: 0039-2944

\section{Notizia bibliografica digitale}

Monica Pavesio, «aurélie chevanelle-couture, Médée, mémoire du théâtre. Une Poétique du mal

(1556-1713)», Studi Francesi [Online], 193 (LXV | I) | 2021, online dal 01 juillet 2021, consultato il 14 octobre 2022. URL: http://journals.openedition.org/studifrancesi/43788 ; DOI: https://doi.org/10.4000/ studifrancesi. 43788

Questo documento è stato generato automaticamente il 14 octobre 2022

\section{(c) (i) (9)}

Creative Commons - Attribuzione - Non commerciale - Non opere derivate 4.0 Internazionale - CC BYNC-ND 4.0

https://creativecommons.org/licenses/by-nc-nd/4.0/ 


\title{
AURÉLIE CHEVANELLE-COUTURE, Médée, mémoire du théâtre. Une Poétique du mal (1556-1713)
}

\author{
Monica Pavesio
}

\section{NOTIZIA}

AURÉLIE CHEVANELLE-COUTURE, Médée, mémoire du théâtre. Une Poétique du mal (1556-1713), Genève, Droz, 2019, «Travaux du Grand Siècle» 50, 198 pp.

1 Tra il 1556 ed il 1713 si contano in Francia ben dieci tragedie dedicate a Medea, la malefica sposa dell'argonauta Giasone, nonostante il personaggio, infanticida e regicida, sia legato, più di altre figure mitologiche, all'essenza profonda ed enigmatica del male.

2 Aurélie Chevanelle-Couture, dopo aver analizzato la ricca bibliografia su Medea, si propone di illustrare come questo mito ancestrale sia direttamente collegato nella Francia del Grand Siècle all'arte drammatica e ne rappresenti la faccia maledetta condannata dai riformisti e poi dai moralisti. Effettivamente, il mito di Medea non si trova in pièces ravvicinate tra loro, ma in alcune tragedie che sembrano scandire $i$ momenti chiave della storia del teatro francese dalla metà del Cinquecento alla fine del XVII secolo. L'autrice ne studia quattro (le tragedie Médée di Jean de La Pérouse del 1556 e di Corneille del 1635, la tragédie à machine La Conquête de la Toison d'Or del 1660 sempre di Corneille e la tragedia Médée di Hilaire de Longepierre del 1694), per interrogarsi sulle differenze nel trattamento del mito in quattro generi teatrali rappresentativi dei rispettivi periodi: la tragedia umanista, la tragedia degli anni Trenta, la tragédie à machine, la tragedia di fine secolo. Il personaggio incarnerebbe, infatti, secondo l'autrice del volume, i tratti originali dell'arte drammatica, direttamente collegata alla rappresentazione del male e del disordine, e ogni sua apparizione in scena catalizzerebbe lo sviluppo di una nuova poetica drammatica. 
3 La prima apparizione del mito in terra francese nel 1553 nella tragedia umanista di Jean de la Pérouse coincide con la prima traduzione scritta in francese della fonte senecana. La seconda nel 1635 è l'atto di nascita del teatro tragico corneliano, una tragedia, come si sa, che, pur essendo una delle prime opere regolari del teatro francese, è incentrata su un personaggio femminile che lotta per affermare la propria autonomia e libertà, il proprio grido di furore, in un mondo che sta andando verso l'ordine e la regolarizzazione. Dopo ben venticinque anni, perché il mito di Medea è anche la storia di un'assenza, la terza apparizione avviene su una scena parallela, quella del teatro in musica, con la tragédie à machine di Corneille, che sarà il modello per le successive rappresentazioni in musica (compresa quella del fratello Thomas che non viene analizzata). Al crepuscolo del Grand Siècle, nel 1694, il personaggio si riafferma sulla scena tragica, con la tragedia di Longepierre, per illustrare la tesi estetica degli Anciens contro i Modernes, nella famosa Querelle che infiammerà gli animi di fine secolo, ma si tratta ormai di un personaggio sbiadito.

4 Un bel percorso, quello illustrato nel volume di Aurélie Chevanelle-Couture, che avrebbe potuto essere esaustivo con l'analisi delle tragédies lyriques di fine Seicento ed inizio Settecento, alle quali l'autrice fa solo un breve accenno, e delle parodie del teatro italiano, che vengono nominate nella conclusione. Una buona bibliografia ed un indice dei nomi completano il volume. 